\title{
Highly Efficient Blue LECs Using Charged Iridium Complexes
}

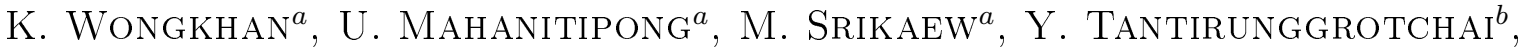 \\ S. SAHASITHIWAT ${ }^{c}$, R. JITCHATI ${ }^{a, *}$ \\ ${ }^{a}$ Department of Chemistry, Faculty of Science,Ubon Ratchathani University, \\ Ubon Ratchathani Province, 34190, Thailand \\ ${ }^{b}$ National Metal and Materials Technology Center, 114 Thailand Science Park, \\ Pahol-yothin Rd., Klong 1, Khlong Luang, Pathumthani 12120, Thailand \\ ${ }^{c}$ Department of Chemistry, Faculty of Science and Technology, \\ Thammasat University, Pathumthani, 12120 Thailand
}

\begin{abstract}
Two heteroleptic charged iridium (III) species comprising two cyclometallating ligands and a neutral diimine ligand were synthesized and characterized, namely [(3,4,7,8-tetramethyl-1,10-phenanthroline-N$\mathrm{N}^{\prime}$ )-bis-(2-(2,4-difluorophenyl)-5-(trifluoromethyl)pyridine- $\left.\mathrm{C}^{6 \prime}, \mathrm{N}\right)$-iridium (III)] hexafluorophosphate (UM01) and $\left[\left(3,4,7,8\right.\right.$-tetramethyl-1,10-phenanthroline-N-N')-bis- $\left(2-\left(2^{\prime}, 4^{\prime}\right.\right.$-difluoro-phenyl $)-1 H$-pyrazole- $\left.{ }^{6 \prime}, \mathrm{N}\right)$-iridium (III)] hexafluorophosphate (UM02). Both complexes were used as the blue emitter in OLED and LEC devices. We found that the optimized structure is ITO/PEDOT:PSS/complex:BMIMPF $6(1: 1) / \mathrm{Al}$. The UM01 gave a current efficiency of $1.14 \mathrm{~cd} \mathrm{~A}^{-1}$, whereas the UM02 shows a better CIE coordination at $0.19,0.40$.
\end{abstract}

DOI: 10.12693/APhysPolA.127.1109

PACS: $85.60 . \mathrm{Bt} ;$ 85.60.Jb

\section{Introduction}

Heteroleptic charged iridium (III) species comprising two cyclometallating ligands and a neutral diimine ligand of generic formula $\left(\mathrm{C}^{\wedge} \mathrm{N}\right)_{2} \operatorname{Ir}\left(\mathrm{N}^{\wedge} \mathrm{N}\right)^{+}$have been of great interest as multifunctional chromophores for advanced optoelectronic applications [1-6]. The key properties of these complexes are their high stabilities, high luminescence quantum yields, short excited state lifetime and tunable emission energies. The photophysical properties of these phosphors can be tuned by varying the ligand or its substituent groups and by the use of additional ancillary ligands [7]. A charged Ir (III) complex is the key component in highly efficient organic light-emitting diodes (OLEDs) and simple device light-emitting electrochemical cells (LECs) [8]. OLEDs and LECs have been made and studied during recent years motivated by their potential for applications in display and lighting. Today, the devices that are still far from experiencing a successful market entrance and many issues have to be solved in order to make them a viable alternative to the current display technologies. One big problem that should be intensive studied is the development of the blue emitter materials $[9,10]$. For example, a charged iridium (III) demonstrated by Henk J. Bolink give a blue-green from LECs with a current efficiency reaching $5.5 \mathrm{~cd} \mathrm{~A}^{-1}$ and a maximum power efficiency of $5.8 \mathrm{Lm} \mathrm{Watt}^{-1}$ [9]. Yong Qiu shows that LECs based on the charged iridium (III) of (2,4-difluorophenyl)-1 $H$-pyrazole and 2-(1(4-tritylphenyl)- $1 H$-imidazol-2-yl)pyridine give highly efficient blue-green electroluminescence with current efficiency, external quantum efficiency, and power efficiency

*corresponding author; e-mail: rukkiat_j@hotmail.com of $18.3 \mathrm{~cd} \mathrm{~A}^{-1}, 7.6 \%$, and $18.0 \mathrm{~lm} \mathrm{~W}^{-1}$, respectively [11]. Here, we developed the electroluminescence based on OLEDs and LECs from a charged iridium (III) complexes.

\section{Experimental}

All the chemicals were purchased from Acros organic and used without further purification, unless otherwise noted. The UM01 and UM02 were synthesized according to the reference by varying the $\mathrm{C}, \mathrm{N}$ ligands [12]. ${ }^{1} \mathrm{H}$ and ${ }^{13} \mathrm{C}$ NMR spectra were recorded on a Bruker Avance 300 spectrometer. Chemical shifts are quoted downfield from internal standard TMS. MS data were obtained using a Thermo Finnigan LTQFT instrument. Ultravioletvisible (UV-vis) spectra were recorded with Perkin-Elmer UV Lambda 25. Photoluminescence spectrum and the fluorescence quantum yields $\left(\Phi_{f}\right)$ were identified by a Perkin-Elmer LS 50B Luminescence Spectrometer the standard quinine sulfate solution in $0.01 \mathrm{M} \mathrm{H}_{2} \mathrm{SO}_{4}$, whose fluorescence quantum yield is known to be 0.54 .

$[(3,4,7,8$-tetramethyl-1,10-phenanthroline-N-N' $)-$ bis-(2-(2,4-difluorophenyl)-5-(trifluoromethyl)pyridine$\left.\mathrm{C}^{6 \prime}, \mathrm{N}\right)$-iridium (III)] hexafluorophosphate (UM01) (84\%); ${ }^{1} \mathrm{H}$ NMR $\left(300 \mathrm{MHz}, \mathrm{CDCl}_{3}\right) \delta 8.51(\mathrm{dd}, J=8.8,2.4 \mathrm{~Hz}$, $1 \mathrm{H}), 8.44(\mathrm{~s}, 1 \mathrm{H}), 8.02(\mathrm{dd}, J=8.9,1.6 \mathrm{~Hz}, 1 \mathrm{H}), 7.95(\mathrm{~s}$, $1 \mathrm{H}), 7.41(\mathrm{~s}, 1 \mathrm{H}), 6.75-6.65(\mathrm{~m}, 1 \mathrm{H}), 5.74(\mathrm{dd}, J=8.1$, $2.3 \mathrm{~Hz}, 1 \mathrm{H}), 2.93(\mathrm{~s}, 3 \mathrm{H}), 2.51(\mathrm{~s}, 3 \mathrm{H}) ; \mathrm{MS}\left(\mathrm{ES}^{+}\right)$ $m / z=945.1627\left(\mathrm{M}^{+}-\mathrm{PF}_{6}, 100\right)$.

[(3,4,7,8-tetramethyl-1,10-phenanthroline-N-N $)$-bis(2-( $2^{\prime}, 4^{\prime}$-difluoro-phenyl)- $1 H$-pyrazole- $\left.{ }^{6 \prime}, \mathrm{N}\right)$-iridium (III)] hexafluorophosphate (UM02) (78\%); ${ }^{1} \mathrm{H} \quad \mathrm{NMR}$ $\left(300 \mathrm{MHz}, \mathrm{CDCl}_{3}\right) \delta 8.36-8.31(\mathrm{~m}, 2 \mathrm{H}), 8.09-8.03(\mathrm{~m}$, $1 \mathrm{H}), 6.86(\mathrm{~d}, J=2.5 \mathrm{~Hz}, 1 \mathrm{H}), 6.77-6.67(\mathrm{~m}, 1 \mathrm{H})$, $6.53-6.50(\mathrm{~m}, 1 \mathrm{H}), 5.83(\mathrm{dd}, J=8.3,2.0 \mathrm{~Hz}, 1 \mathrm{H})$, $2.88(\mathrm{~s}, 3 \mathrm{H}), 2.48(\mathrm{~s}, 3 \mathrm{H}) ; \mathrm{MS}\left(\mathrm{ES}^{+}\right) \mathrm{m} / z=787.1784$ $\left(\mathrm{M}^{+}-\mathrm{PF}_{6}, 100\right)$. 
The electroluminescence of iridium complex was dissolved in acetonitrile solution at a concentration of $12.5 \mathrm{mg} \mathrm{ml}^{-1}$. Prior to the fabrication of the electroluminescence, the ITO glass substrates were thoroughly cleaned followed by UV-ozone treatment for $10 \mathrm{~min}$. A thin film of poly (3,4ethylenedioxythiophene):poly(styrenesulfonate) (PEDOT:PSS) layer was spin-coated at $3000 \mathrm{rpm}$ for $180 \mathrm{~s}$ and baked at $260^{\circ} \mathrm{C}$ for $10 \mathrm{~min}$. For the host-guest OLED device, the emitter layer was spin-coated with the host 2-(4-poly(9-vinylcarbazole) (PVK) and 2(4-tert-butylphenyl)-5-(4-biphenylyl)-1,3,4-oxadiazole (PBD) in $3: 1 \mathrm{w} / \mathrm{w}$ with the complex followed by 1,3,5-tris(2-N-phenylbenzimidazolyl)benzene (TPBi), $\mathrm{LiF}$ and aluminum cathode with a shadow mask under high vacuum. For simple LEC device, the complex films were spin-coated with or without 1-butyl-3methylimidazolium (BMIM) $\mathrm{PF}_{6}$ by varied the mole ratios and then capped with aluminum cathode. The electroluminescent properties of the resultant devices were performed using a Keithley 2400 source meter, as a power supply and multimeter, a Minolta LS-110, as a luminance detector, and an Ocean optics USB4000 spectrometer.

\section{Results and discussions}

The molecular structure of target charged iridium (III)complexes is depicted in Fig. 1. UM01 and
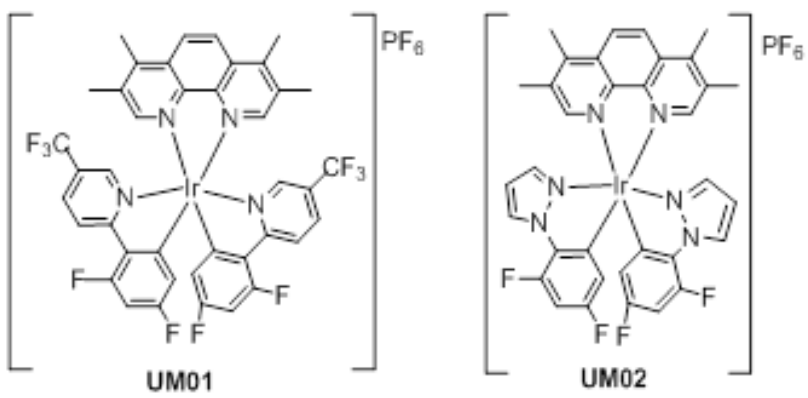

Fig. 1. The molecular structure of UM01 and UM02.

UM02 in dichloromethane (DCM) were characterized using UV-visible absorbance and fluorescence spectroscopy as shown in Fig. 2. The complex displays strong absorption bands between 250 and $300 \mathrm{~nm}$ which can be attributed to ligand-centered (LC) of the cyclometalated phenyl pyridine (ppy) and phenanthroline (phen). While, the weaker absorption bands about $400 \mathrm{~nm}$ and above can be assigned to metal- to-ligand charge transfer (MLCT). These characteristic are consistent with the previously reported in the literatures $[13,14]$. The emission wavelengths of the both complexes were found around $480 \mathrm{~nm}$ which is compared to the blue-green color. We found that both UM01 and UM02 give the quantum yield of 0.01 . We carried out DFT calculations to obtain the molecular geometries and electronic information of the charged iridium (III) complexes. The geometries of UM01 and UM02

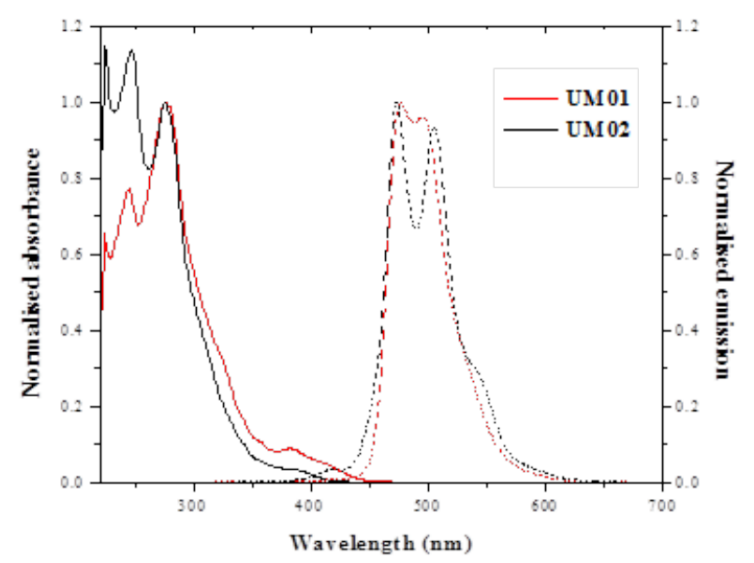

Fig. 2. UV-Vis absorption and emission of UM01 and UM02 in dichloromethane at room temperature.

were optimized at B3LYP/6-31G*:LANL2DZ. The frontier orbital and energy gap of UM02 are shown in Fig. 3 where the LUMO is located on the phenanthroline ligand and the HOMO involves the iridium and phenylene groups (Fig. 3). The calculated energy gap of UM02 shows a value at $3.37 \mathrm{eV}$ which is in agreement with the result from photophysical experiments $(3.10 \mathrm{eV})$.

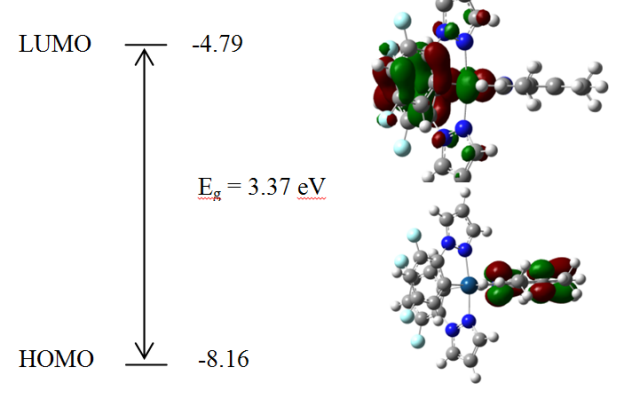

Fig. 3. HOMO and LUMO energies and corresponding orbital contours of UM02 by B3LYP/631G*:LANL2DZ. The $\mathrm{E}_{g}$ is defined as the HOMOLUMO energy gap.

In order to evaluate the electroluminescent properties, complexes were first employed as emitting layer in both host-guest LECs [15] and OLEDs [16, 17] where PVK and PBD were mixed as the co-host. PEDOT:PSS acts as hole-injecting layer to facilitate electron transport. TPBi was used as an electron-transport/hole-blocking layer. Unfortunately, both host-guest LEC and OLED devices show weak current efficiency less than $0.2 \mathrm{~cd} \mathrm{~A}^{-1}$. This can be explained by the unsuitable energy level of UM01 and host material [18]. Recently, the efficiency of the LECs devices can be improved by the addition of ionic liquid (IL) [19-21]. To investigate, we optimized the mole ratio of $\mathrm{BMIMPF}_{6}$. We found that LEC structure: ITO/PEDOT:PSS/UM01:BMIMPF ${ }_{6}(1: 1) / \mathrm{Al}$ was the efficient device with a maximum brightness of $1.037 \mathrm{~cd} \mathrm{~m}^{-2}$ and a current efficiency of $1.14 \mathrm{~cd} \mathrm{~A}^{-1}$ (see Figure 4). With the same structure, we used UM02 as the emitter 


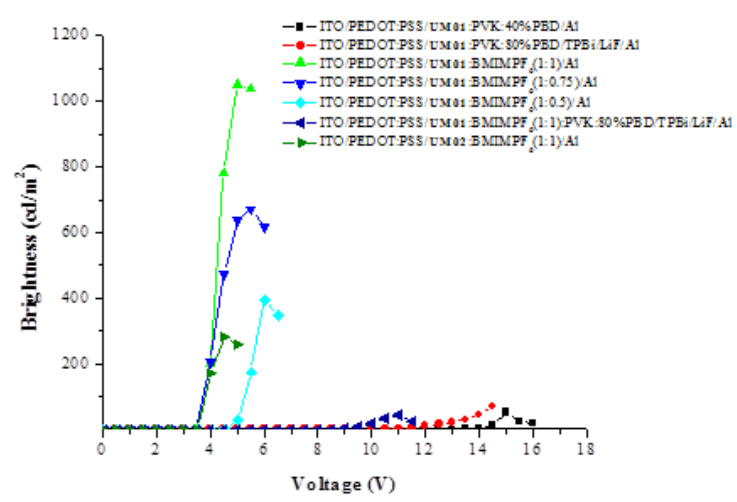

Fig. 4. Brightness versus voltage curves of the device based on UM01 and UM02 with a different structure.

LEC and OLED device performances of TABLE I UM01 and UM02.

\begin{tabular}{|c|c|c|c|c|c|}
\hline $\begin{array}{c}\text { ITO/PEDOT: } \\
\text { PSS } / . .\end{array}$ & $\begin{array}{c}V_{\text {turn on }} \\
{[\mathrm{V}]}\end{array}$ & \begin{tabular}{|c|c}
$\mathrm{L}_{\max }$ \\
{$\left[\mathrm{cdm}^{-2}\right]$}
\end{tabular} & $\begin{array}{c}\eta_{c \max } \\
{\left[\mathrm{cd} \mathrm{A} \mathrm{A}^{-1}\right]}\end{array}$ & $\begin{array}{c}\eta_{p \max } \\
{\left[1 \mathrm{~lm} \mathrm{~W}^{-1}\right]}\end{array}$ & $\begin{array}{l}\text { CIE } \\
(\mathrm{x}, \mathrm{y})\end{array}$ \\
\hline $\begin{array}{c}\ldots \text { UM01: } \\
\text { PVK: } 40 \% \text { PBD } / \mathrm{Al}\end{array}$ & 13.5 & 52 & 0.04 & 0.01 & $\mathrm{~N} / \mathrm{A}$ \\
\hline $\begin{array}{c}\text {... UM01: } \\
\text { PVK:80\%PBD/ } \\
\text { TPBi/LiF/Al }\end{array}$ & 10.6 & 70 & 0.12 & 0.03 & $\mathrm{~N} / \mathrm{A}$ \\
\hline $\begin{array}{c}\ldots \text { UM01: }^{2} \\
\text { BMIMPF }_{6} \\
(1: 1) / \mathrm{Al}\end{array}$ & 3.6 & 1037 & 1.14 & 0.80 & $0.23,0.43$ \\
\hline $\begin{array}{l}\ldots \text { UM01: } \\
\text { BMIMPF }_{6} \\
(1: 0.75) / \mathrm{Al}\end{array}$ & 3.5 & 670 & 0.68 & 0.48 & $0.24,0.45$ \\
\hline $\begin{array}{c}\ldots \mathrm{UM} 01: \\
\mathrm{BMIMPF}_{6} \\
(1: 0.5) / \mathrm{Al}\end{array}$ & 4.5 & 396 & 0.49 & 0.26 & $0.24,0.44$ \\
\hline $\begin{array}{c}\ldots \mathrm{UM}^{2} 1: \\
\text { BMIMPF }_{6}(1: 1): \\
\text { PVK:80\%PBD/ } \\
\mathrm{TPBi} / \mathrm{LiF} / \mathrm{Al}\end{array}$ & 8.6 & 44 & 0.08 & 0.03 & $\mathrm{~N} / \mathrm{A}$ \\
\hline $\begin{array}{c}\text {.. UM02: } \\
\text { BMIMPF }_{6} \\
(1: 1) / \mathrm{Al}\end{array}$ & 3.6 & 282 & 0.80 & 0.63 & $0.19,0.40$ \\
\hline
\end{tabular}

in LECs. We found that the UM02 give a better blue CIE coordinate at $0.19,0.40$. However, the device shows a lower current efficiency of $0.08 \mathrm{~cd} \mathrm{~A}^{-1}$. Detailed electroluminescent characteristics are summarized in Table I and Fig. 4.

\section{Conclusions}

The blue electroluminescence LECs can be achieved with the charged iridium (III) complexes. We found that the current efficiency can be improved to $1.14 \mathrm{~cd} \mathrm{~A}^{-1}$ by the addition of $\mathrm{IL}$ at 1:1 mole ratio into the emitting layer. The complex with $\mathrm{C}, \mathrm{N}$ pyrazole ligand give a blue CIE coordination at $0.19,0.40$. Therefore, this research may be a useful and helpful data to develop an efficient real blue electroluminescence LECs in the future.

\section{Acknowledgments}

This work was financially supported by the Thailand Research Fund, the Higher Education Commission and
Ubon Ratchathani University (MRG5480005). U. Mahanitipong thanks to YSTP and M. Srikaew thanks to SAST for the scholarships.

\section{References}

[1] K.K.-W. Lo, S.P.-Y. Li, K.Y. Zhang, New J. Chem. 35, 265 (2011).

[2] Q. Zhao, S.-J. Liu, W. Huang, Macromol. Rapid Commun. 31, 794 (2010).

[3] C. Ulbricht, B. Beyer, C. Friebe, A. Winter, U.S. Schubert, Adv. Mater. 21, 4418 (2009).

[4] J.A.G. Williams, A.J. Wilkinson, V.L. Whittle, Dalton Trans., 2081 (2008).

[5] M.S. Lowry, S. Bernhard, Chem. Eur. J. 12, 7970 (2006).

[6] W.-Y. Wong, C.-L. Ho, J. Mater. Chem. 19, 4457 (2009).

[7] C.D. Sunesh, G. Mathai, Y. Choe, Org. Electron. 15, 667 (2014).

[8] U. Mitschke, P. Baüerle, J. Mater. Chem. 10, 1471 (2000).

[9] H.J. Bolink, L. Cappelli, S. Cheylan, E. Coronado, R.D. Costa, N. Lardies, M.K. Nazeeruddin, E. Ort1, J. Mater. Chem. 17, 5032 (2007).

[10] M.K. Nazeeruddin, R.T. Wegh, Z. Zhou, C. Klein, Q. Wang, F. De Angelis, S. Fantacci, M. Grätzel, Inorg. Chem. 45, 9245 (2006).

[11] L. He, L. Duan, J. Qiao, G. Dong, L. Wang, Y. Qiu, Chem. Mater. 22, 3535 (2010).

[12] C. Rothe, C.-J. Chiang, V. Jankus, K. Abdullah, X. Zeng, R. Jitchati, A.S. Batsanov, M.R. Bryce, A.P. Monkman, Adv. Funct. Mater. 19, 2038 (2009).

[13] F. De Angelis, S. Fantacci, N. Evans, C. Klein, S.M. Zakeeruddin, J.E. Moser, K. Kalyanasundaram, H.J. Bolink, M. Grätzel, M.K. Nazeeruddin, Inorg. Chem. 46, 5989 (2007).

[14] A.B. Tamayo, S. Garon, T. Sajoto, P.I. Djurovich, I.M. Tsyba, R. Bau, M.E. Thompson, Inorg. Chem. 44, 8723 (2005).

[15] L. He, L. Duan, J. Qiao, D. Zhang, L. Wang, Y. Qiu, Org. Electron. 11, 1185 (2010).

[16] P. Wongkaew, U. Mahanitipong, N. Wongsang, S. Sahasithiwat, R. Jitchati, e-J. Surf. Sci. Nanotech. 12, 141 (2014).

[17] H. Tang, Y. Li, Q. Chen, B. Chen, Q. Qiao, W. Yang, H. Wu, Y. Cao, Dyes and Pigments 100, 79 (2014).

[18] W.S. Jeon, T.J. Park, S.Y. Kim, R. Pode, J. Jang, J.H. Kwon, Org. Electron. 10, 240 (2009).

[19] L. He, L. Duan, J. Qiao, D. Zhang, G. Dong, L. Wang, Y. Qiu, Synth. Met. 166, 52 (2013).

[20] S.T. Parker, J.D. Slinker, M.S. Lowry, M.P. Cox, S. Bernhard, G.G. Malliaras, Chem. Mater. 17, 3187 (2005).

[21] H.-F. Chen, W.-Y. Hung, S.-W. Chen, T.-C. Wang, S.-W. Lin, S.-H. Chou, C.-T. Liao, H.-C. Su, H.A. Pan, P.-T. Chou, Y.-H. Liu, K.-T. Wong, Inorg. Chem. 51, 12114 (2012). 